\title{
ANALYTIC HIERARCHY PROCESS (AHP) APPROACH FOR SELECTION OF OPEN CAST COAL MINE PROJECT
}

\author{
Satya Mandal \\ Registrar at Diamond Harbour Women's University, \\ South 24 Parganas, West Bengal, India \\ Dr. Seema Sarkar Mondal \\ Associate Professor in the Department, Mathematics, \\ NIT, Durgapur, India
}

\begin{abstract}
Open cast coal mine project selection decision is one of the crucial decisions for the corporate level managers and engineers of coal producing company. Choosing a suitable open cast mining project to carry out extraction from the coal deposit is a very important in terms of the economics, safety, productivity and other tangible and intangible criteria the projects of open cast coal mines. In this research paper we have taken five real projects and ten criteria. Some of the criteria are fully subjective in nature. The best project is selected considering relative weight of these ten criteria. Analytic Hierarchy Process technique has been applied to select the best project.
\end{abstract}

Key words: Analytic Hierarchy Process (AHP), Open Cast Coal Mine, Pair Wise Comparison matrix, Consistency Index, Random Index, Consistency Ratio, Normalized Matrix, Priority Vector.

Cite this Article: Satya Mandal and Dr. Seema Sarkar Mondal. Analytic Hierarchy Process (AHP) Approach for Selection of Open Cast Coal Mine Project, International Journal of Industrial Engineering Research and Development, 7(2), 2016, pp. 1-13

https://iaeme.com/Home/issue/IJIERD?Volume=7\&Issue=2

\section{INTRODUCTION}

Open cast mine project selection is one of most important decisions taken by the corporate level manger. Managers often encounter the problems of choosing a project from among the different alternative projects. Experiences show that the final decision is often made on the intuitive basis partially because of lack of formal framework for systematic selection [1]. A wide range of approaches has been reported in the formalizing and rationalizing this type of decision situations. The quantitative methods range from simple ranking procedure for individual projects, occasionally 
making use of decision tree type structures to those that consider portfolio types of projects and which often take the form of mathematical models [2]. Simple ranking procedures are normally implemented involving indices like, net present value (N.P.V), rate of return and cost benefit ratio. In the portfolio type of models it is possible to choose a set of projects which maximize some achievement function subject to meeting a specified set of constraints.

But there are many circumstances in which key data for decision-making are qualitative in nature. Sometimes collection of more precise information or data is not feasible because of cost or urgency and sometimes there exists some important variables which involve human factors and which cannot be quantified using any objective scale [3].

Yasanur Kayikci [4] has studied the applicability of the way for the development of a conceptual model based on a combination of the fuzzy-analytical hierarchy process and artificial neural networks methods in the process of decision-making in order to select the most appropriate location. The article written by Licinio da Silva Portugal, Andrea Vaz Morgado, Orlando Lima Junior [5] presents a procedure for establishing and ranking the areas that are candidates for builders truck cargo terminals, based on the analytic hierarchy process (AHP) and considering location factor with focus on accessibility considerations, expressed by indicators derived from graph theory. Ali Yousefi, and Abdollah Hadi-Vencheh[6] proposed an integrated model from the most important and usable MCDM (Multi Criteria Decision Making) technique, AHP and techniques for ordering preference by similarity to ideal solution in order to examine the improvement fields of Iran automobile industry. Mehmet Ekmekcioglu, Tolga Kaya and Cengiz Kahraman[7] in their paper described a modified fuzzy TOPSIS (Techniques for Order of Preference by Similarity to Ideal Solution) methodology for selection of appropriate disposal method and site for municipal solid waste. The weights of the selection criteria are determined by fuzzy pairwise comparison matrices of Analytic Hierarchy Process (AHP). Reza Rostamzadeh and Saudah Sofian[8] have used a systematic MCDM approach to seven production inputs which named as 7Ms (management, Manpower, Marketing, Method ,Machine, Material and Money).Linguistic values were used to assess the ratings and weights for $7 \mathrm{Ms}$. These linguistic ratings can be expressed in trapezoidal or triangular fuzzy numbers. Then MCDM model based on fuzzy theory including FAHP (Fuzzy Analytic Hierarchy Process) and FTOPSIS (Fuzzy Techniques for Order of reference by Similarity to Ideal Solution) were applied. The results obtained from AHP, FAHP, FTOPSIS were compared with each other. The research paper of Nahid Mohajeri and Gholam R. Amin[9] deals with the problem of finding the optimum site for a railway station for the city of Mashhad, northest Iran, using the methods of Analytical hierarcy process (AHP) and data envelopment analysis(DEA).

In recent years, determining the best suppliers has become a key strategic consideration in the competitive market. Since the decision commomly involves evaluationg different criteria or attributes, suppliers selection is a multiple criteria decision making (MCDM) problem. The study of Chin-Nung Liao and Hsing -Pei Kao[10] integrates the Taguchi loss function, AHP and multi-choice goal programming(MCGP) model for solving the supplier selection problem. MCDM has been used by Semih Onut and Selin Soner[11] for selection of waste materials location. In their paper a fuzzy TOPSIS based methodology was applied to solve the solid waste transshipment site selection problem in Istanbul, Turkey. The criteria weights were calculated by using the AHP. Vukotic Ivana and Kecojevic 
Vladislav[12] used MADM approach for selection of rope shovels operators in open cast mine. Their MADM model consists of attributes, weights of importance and alternatives.

The AHP can be very useful in involving several decision makers with different conflicting objectives to arrive at a consensus decision. A. Bascetin[13] has used an AHP based model for the optimal selection of reclamation method for an open pit mine situated in Turkey. Mahmut Yavuz, Melih Iphar and Guner Once[14] presented an application of the AHP method to the selection of the optimum support design for the main transport road which had been planned for deep coal seam panels of Weatern Lignite Corporation Tuncbilek in Turkiye.

Very little research work has been done for open cast coal mine project selection using any operations research tools and techniques. Engineers can frequently encounter with the situation to select the best open cast coal mine project from a group of alternative projects. In this research work we have tried to identify how AHP models can be used to select the best project from a group of alternative projects. The primary aim of this paper is to provide new modeling and solution techniques in the areas of project selection of open cast coal mines. For simplicity we have taken five opencast coal mine projects and ten criteria.

\section{AHP METHODOLOGY}

Decision analysis involves use of rational process for selecting the best of several alternatives. The goodness of a selected alternative depends on the quality of the data used in describing the decision making situation. From this standpoint, a decision making process can fall into one of the three categories [15]:

- Decision making under certainty in which the data are known deterministically.

- Decision making under risk in which the data can be described by probability distributions.

- Decision making under uncertainty in which the data cannot be assigned any weigh that represent their degree of relevance in the process.

The LP models are examples of decision making under certainty. AHP models are also falling under special category of decision making under certainty.

AHP is designed for situations in which ideas, and emotions are quantified based on subjective judgment to provide a numeric scale for prioritizing decision alternatives[16]. The Analytic Hierarchy Process (AHP), is a procedure designed to quantify managerial judgments of the relative importance of each of several conflicting criteria used in the decision making process.

The AHP is a multi-criteria decision method that uses hierarchical structures to represent a problem [17]. Priorities for alternatives are then developed based on the judgment of the user. The following steps are used for AHP methods:-

Step 1: List the Overall Goal, Criteria, and Decision Alternatives

Step 2: Develop a Pair-wise Comparison Matrix

Rate the relative importance between each pair of decision alternatives. The matrix lists the alternatives horizontally and vertically and has the numerical ratings comparing the horizontal (first) alternative with the vertical (second) alternative. 


\section{Ratings are given as follows}

Compared to the second

Alternative, the first alternative is:

Extremely preferred

Numerical rating

Very strongly preferred

9

Strongly preferred

Moderately preferred

Equally preferred

Intermediate numeric ratings of $8,6,4$, and 2 can be assigned. A reciprocal rating (i.e. $1 / 9,1 / 8$, etc.) is assigned when the second alternative is preferred to the first. The value of 1 is always assigned when comparing an alternative with itself.

Step 3: Develop a Normalized Matrix: Divide each number in a column of the pairwise comparison matrix by its column sum.

Step 4: Develop the Priority Vector: Average each row of the normalized matrix. These row averages form the priority vector of alternative preferences with respect to the particular criterion. The value of this vector sum is equal to 1 .

Step 5: Calculate a Consistency Ratio: The consistency of the subjective input in the pair-wise comparison matrix can be measured by calculating a consistency ratio. A consistency ratio of less than .1 is good. For ratios which are greater than .1 , the subjective input should be re-evaluated.

\subsection{Steps For Determining Consistency Ratio:}

Step 5.1.1: For each row of the pair-wise comparison matrix, determine a weighted sum by summing the multiples of the entries by the priority of its corresponding (column) alternative.

Step 5.1.2: For each row, divide its weighted sum by the priority of its corresponding (row) alternative.

Step 5.1.3: Determine the average, $\lambda_{\max }$, of the results of step 5.1. 2 .

Step 5.1.4: Compute the consistency index, CI, of the $n$ alternatives by: CI $=\left(\lambda_{\max }-\right.$ $n) /(n-1)$.

Step 5.1.5: Determine the random index, RI, as follows:

Number of Random Number of Random

Alternative (n) Index (RI) Alternative (n) Index (RI)

$\begin{array}{llll}3 & 0.58 & 6 & 1.24 \\ 4 & 0.90 & 7 & 1.32 \\ 5 & 1.12 & 8 & 1.41\end{array}$

Step 5.1.6:

Compute the consistency ratio: $\mathrm{CR}=\mathrm{CI} / \mathrm{RI}$.

The closer the consistency ratio is to zero is the greater the consistency. If it is high, it means the input judgments are not consistent. Hence they have to be elicited again. In general consistency ratio of about $10 \%$ or less is usually considered acceptable. Otherwise, the inconsistency is high and the decision maker is advised to revise the rating in the comparison matrix to realize a more consistent matrix.

Step 6: Develop a Priority Matrix: After steps 2 through 5 have been performed for all criteria. 
Step 7: Develop a Criteria Pair-wise comparison Matrix: This is done in the same manner as that used to construct alternative pair-wise comparison matrices by using subjective ratings (step 2). Similarly, normalize the matrix (step 3) and develop a criteria priority vector (step 4).

Step 8: Develop an Overall Priority Vector:

Multiply the criteria priority vector (from step 7) by the priority matrix (from step 6).

\section{PROBLEM DESCRIPTION}

We have collected data of five open cast coal mines from a reputed company in India. The data of the five projects are shown in the table 1. All these data are quantitative in nature.

Table 1 Data of five open cast coal mine projects.

\begin{tabular}{|l|l|l|l|l|l|}
\hline \multicolumn{1}{|c|}{ Criteria } & Project:1 & Project:2 & Project3 & Project:4 & Project:5 \\
\hline 1. Manpower requirement & 495 & 3024 & 2751 & 1100 & 975 \\
\hline $\begin{array}{l}\text { 2. Foreign Capital requirement in Rs } \\
\text { Lakh }\end{array}$ & 356.78 & 0 & 2105 & 195 & 285 \\
\hline 3. NPV (in lakh Rs ) & 2.3 & 4.5 & 5.4 & 1.7 & 2.5 \\
\hline 4. OMS (ton/manshift) & 3.06 & 1.3 & 2.37 & 2.6 & 5.6 \\
\hline 5. R.O.I (\%) & 18 & 8.05 & 9.71 & 13 & 19 \\
\hline 6. Production('000 ton) & 450 & 250 & 500 & 150 & 550 \\
\hline
\end{tabular}

We have selected four more qualitative criteria in addition to the above six quantitative criteria. These criteria have been selected after discussing the experts in this field.

\section{Six quantitative criteria:}

1. Manpower requirement (MP).

2. Foreign exchange (FCR) requirement [18].

3. Net present value (NPV).

4. Output per man shift (OMS).

5. Return on Investment (ROI).

6. Annual quantity of production (PROD).

Four qualitative criteria [19] are as follows:

7. Social cost benefit impact (SCBI).

8. Environmental impact (EI).

9. Technological impact (TI).

10. Relative importance from consumer view points (RICVP).

The problem is the selection of the best open cast coal mine project considering these ten criteria.

\section{SOLUTION}

The first step in AHP is to develop a graphical representation (Fig.1) of the problem in terms of the overall goal, the criteria to be used and the decision alternative. Such a graph depicts the hierarchy for the problem. Our problem has single hierarchy. 


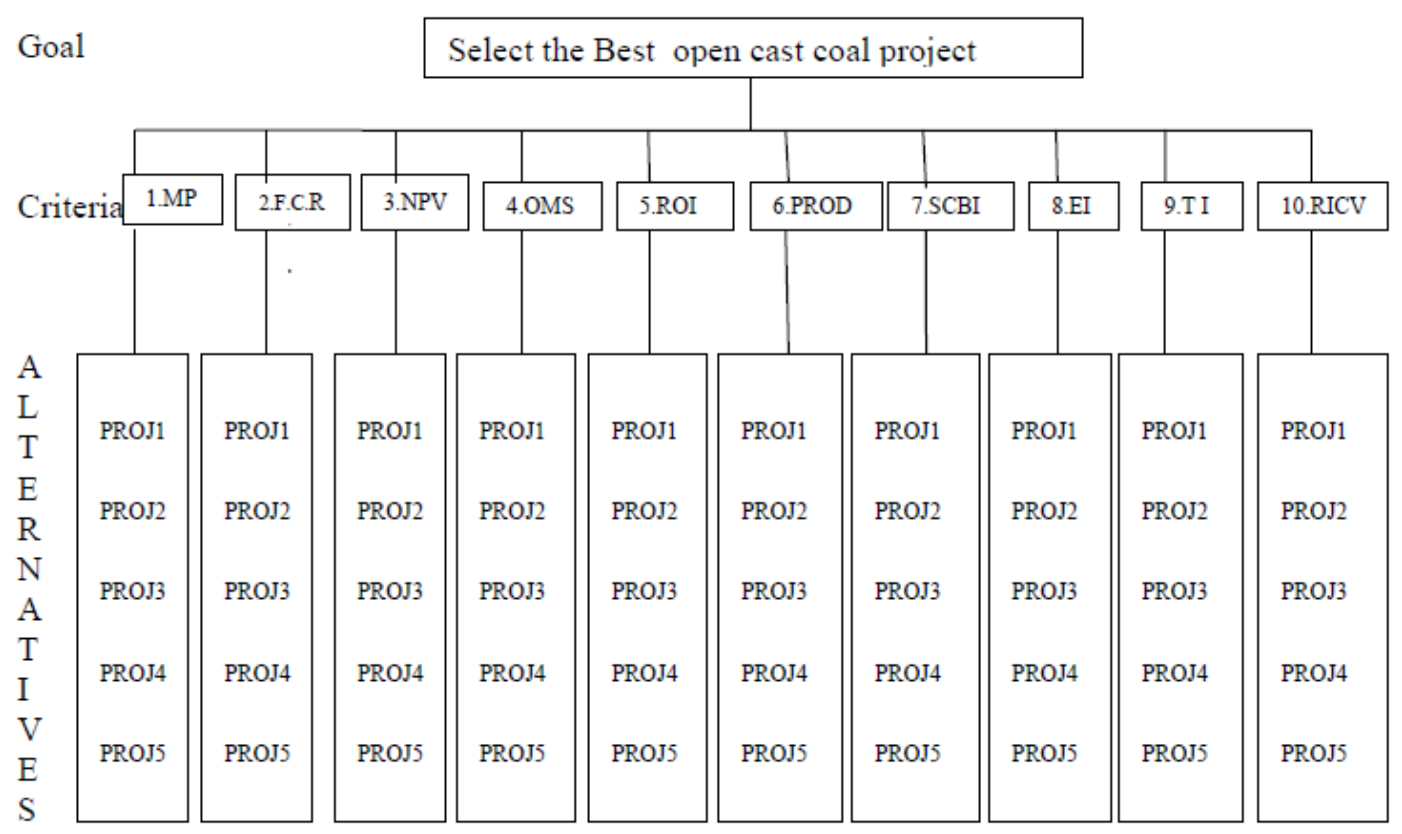

Figure 1 Select the Best Open Cast Coal Mine Project

A decision making team had been formed with two mining engineers of well known coal producing company of India. This team has been asked to give the ratings of pairwise comparison matrix. The comparison matrix for each criterion and its normalized matrices are shown in the table 2 and table 3 respectively. In case of inconsistency (when $\mathrm{CR}>0.1$ ), the team has been asked to revise the pairwise comparison matrix. All the calculations have been made as per the AHP methodology mentioned in section 2 .

Table 2 Pair wise comparison matrix for manpower (MP).

\begin{tabular}{|l|l|l|l|l|l|}
\hline \multicolumn{1}{|c|}{ PROJECTS } & \multicolumn{1}{|c|}{2} & \multicolumn{1}{|c|}{3} & \multicolumn{1}{c|}{4} & \multicolumn{1}{c|}{5} \\
\hline 1 & 1 & 6 & 5 & 3 & 2 \\
\hline 2 & 0.166667 & 1 & 1 & 0.333 & 0.333 \\
\hline 3 & 0.2 & 1 & 1 & 0.333 & 0.333 \\
\hline 4 & 0.333 & 3 & 3 & 1 & 1 \\
\hline 5 & 0.5 & 3 & 3 & 1 & 1 \\
\hline
\end{tabular}

In table 2 the element $(1,3)$ is 5 i.e. project 1 is strongly preferred to project 3 from the view point of manpower (MP). And also the element $(3,1)$ is inverse of 5 i.e. $1 / 5=0.2$. Similarly, element $(4,2)$ in the table is 3 . It signifies that the project 4 is moderately preferred to project 2 in respect of manpower (MP) criteria. The element $(2,4)$ is inverse of 3 i.e. $1 / 3=0.333$. In this way the whole pairwise comparison matrix for manpower is formed by the team of decision maker seeing the quantitative value of manpower (open cast project data) from the table 1.

In the similar fashion the pairwise comparison matrix for other criteria like FCR,NPV, OMS, ROI, PROD, SCBI, EI,TI, RICVP are prepared by the team of decision maker and are shown in the table 5,6,7,8,9,10,11,12,13 respectively. 
Satya Mandal and Dr. Seema Sarkar Mondal

Table 3 Normalized matrix for manpower (MP)

\begin{tabular}{|l|l|l|l|l|l|}
\hline PROJECTS & 1 & 2 & 3 & 4 & 5 \\
\hline 1 & 0.45461 & 0.42857 & 0.38462 & 0.52947 & 0.42863 \\
\hline 2 & 0.07577 & 0.07143 & 0.07692 & 0.05877 & 0.07137 \\
\hline 3 & 0.09092 & 0.07143 & 0.07692 & 0.05877 & 0.07137 \\
\hline 4 & 0.15139 & 0.21429 & 0.23077 & 0.17649 & 0.21432 \\
\hline 5 & 0.22731 & 0.21429 & 0.23077 & 0.17649 & 0.21432 \\
\hline
\end{tabular}

This normalized matrix (table 3 ) is prepared from the table 2 following the step 2 mentioned in Section 2(AHP METHODOLOGY).

$\mathrm{CR}=0.009$, This is also prepared following the step 5 mentioned in section 2(AHP METHODOLOGY).

Table 4 Priority vector for manpower (MP)

\begin{tabular}{|c|}
\hline Priority Vector \\
\hline 0.44518 \\
\hline 0.07085 \\
\hline 0.07388 \\
\hline 0.19745 \\
\hline 0.21263 \\
\hline
\end{tabular}

The summation of the priority vector is always $=1.0$. This table 4 is prepared following the step 4 mentioned in section 2(AHP METHODOLOGY).

Similarly, the pairwise comparison matrix, normalized matrix and priority vector for all the other nine criteria can be formed. Only comparison matrices and consistency ratio (CR) are shown for simplicity in tables (5-13).

Table 5 Pairwise Comparison matrix for FCR

\begin{tabular}{|l|l|l|l|l|l|}
\hline PROJECTS & 1 & 2 & 3 & 4 & 5 \\
\hline 1 & 1 & 0.142857 & 4 & 0.333 & 0.5 \\
\hline 2 & 7 & 1 & 9 & 3 & 5 \\
\hline 3 & 0.25 & 0.111 & 1 & 0.2 & 0.333 \\
\hline 4 & 3 & 0.333 & 5 & 1 & 2 \\
\hline 5 & 2 & 0.2 & 3 & 0.5 & 1 \\
\hline
\end{tabular}

$\mathrm{CR}=0.046$

Table 6 Pairwise Comparison matrix of NPV

\begin{tabular}{|l|l|l|l|l|l|}
\hline PROJECTS & 1 & 2 & 3 & 4 & 5 \\
\hline 1 & 1 & 0.5 & 0.5 & 2 & 1 \\
\hline 2 & 2 & 1 & 0.333 & 2 & 4 \\
\hline 3 & 2 & 3 & 1 & 5 & 4 \\
\hline 4 & 0.5 & 0.5 & 0.25 & 1 & 0.5 \\
\hline 5 & 1 & 0.25 & 0.33 & 2 & 1 \\
\hline
\end{tabular}

$\mathrm{CR}=0.089$ 
Analytic Hierarchy Process (AHP) Approach For Selection of Open Cast Coal Mine Project

Table 7 Pairwise Comparison matrix of OMS

\begin{tabular}{|l|l|l|l|l|l|}
\hline PROJECTS & 1 & 2 & 3 & 4 & 5 \\
\hline 1 & 1 & 5 & 2 & 3 & 0.5 \\
\hline 2 & 0.2 & 1 & 0.5 & 0.333 & 0.2 \\
\hline 3 & 0.5 & 2 & 1 & 0.5 & 0.25 \\
\hline 4 & 0.333 & 3 & 2 & 1 & 0.333 \\
\hline 5 & 2 & 5 & 4 & 3 & 1 \\
\hline
\end{tabular}

$\mathrm{CR}=0.036$

Table 8 Pairwise Comparison matrix of ROI

\begin{tabular}{|l|l|l|l|l|l|}
\hline PROJECTS & 1 & 2 & 3 & 4 & 5 \\
\hline 1 & 1 & 2 & 2 & 3 & 1 \\
\hline 2 & 0.5 & 1 & 1 & 0.333 & 0.25 \\
\hline 3 & 0.5 & 1 & 1 & 0.5 & 0.333 \\
\hline 4 & 0.333 & 3 & 2 & 1 & 0.5 \\
\hline 5 & 1 & 4 & 3 & 2 & 1 \\
\hline
\end{tabular}

$\mathrm{CR}=0.048$

Table 9 Pairwise Comparison matrix of PROD

\begin{tabular}{|l|l|l|l|l|l|}
\hline PROJECTS & 1 & 2 & 3 & 4 & 5 \\
\hline 1 & 1 & 0.333 & 0.2 & 1 & 0.125 \\
\hline 2 & 3 & 1 & 0.333 & 2 & 0.333 \\
\hline 3 & 5 & 3 & 1 & 4 & 0.5 \\
\hline 4 & 1 & 0.5 & 0.25 & 1 & 0.2 \\
\hline 5 & 8 & 3 & 2 & 5 & 1 \\
\hline
\end{tabular}

$\mathrm{CR}=0.019$

Table 10 Pairwise Comparison matrix of SCBI

\begin{tabular}{|l|l|l|l|l|l|}
\hline PROJECTS & 1 & 2 & 3 & 4 & 5 \\
\hline 1 & 1 & 3 & 4 & 3 & 2 \\
\hline 2 & 0.333 & 1 & 1 & 1 & 0.5 \\
\hline 3 & 0.25 & 1 & 1 & 0.5 & 0.2 \\
\hline 4 & 0.333 & 1 & 2 & 1 & 0.333 \\
\hline 5 & 0.5 & 2 & 5 & 3 & 1 \\
\hline
\end{tabular}

$\mathrm{CR}=0.033$

Table 11 Pairwise Comparison matrix of EI

\begin{tabular}{|l|l|l|l|l|l|}
\hline PROJECTS & 1 & 2 & 3 & 4 & 5 \\
\hline 1 & 1 & 0.5 & 1 & 2 & 1 \\
\hline 2 & 2 & 1 & 2 & 3 & 2 \\
\hline 3 & 1 & 0.5 & 1 & 2 & 1 \\
\hline 4 & 0.5 & 0.333 & 0.5 & 1 & 0.5 \\
\hline 5 & 1 & 0.5 & 1 & 2 & 1 \\
\hline
\end{tabular}

$\mathrm{CR}=0.0023$ 
Satya Mandal and Dr. Seema Sarkar Mondal

Table 12 Pairwise Comparison matrix of TI

\begin{tabular}{|l|l|l|l|l|l|}
\hline PROJECTS & 1 & 2 & 3 & 4 & 5 \\
\hline 1 & 1 & 0.333 & 2 & 1 & 1 \\
\hline 2 & 3 & 1 & 5 & 3 & 3 \\
\hline 3 & 0.5 & 0.2 & 1 & 0.333 & 0.5 \\
\hline 4 & 1 & 0.333 & 3 & 1 & 1 \\
\hline 5 & 1 & 0.333 & 2 & 1 & 1 \\
\hline
\end{tabular}

$\mathrm{CR}=0.007$

Table 13 Pairwise Comparison matrix of RICVP

\begin{tabular}{|l|l|l|l|l|l|}
\hline PROJECTS & 1 & 2 & 3 & 4 & 5 \\
\hline 1 & 1 & 5 & 3 & 1 & 4 \\
\hline 2 & 0.5 & 1 & 0.333 & 0.166667 & 0.5 \\
\hline 3 & 0.333 & 3 & 1 & 0.25 & 2 \\
\hline 4 & 1 & 6 & 4 & 1 & 5 \\
\hline 5 & 0.25 & 2 & 0.5 & 0.2 & 1 \\
\hline
\end{tabular}

$\mathrm{CR}=0.093$

Table 14a Pair wise comparison matrix of ten criteria. This table is prepared the way we prepared the table 2.

\begin{tabular}{|l|l|l|l|l|l|l|l|l|l|l|l|}
\hline & 1MP & 2FCR & 3NPV & 4OMS & 5ROI & 6PROD & 7SCBI & 8EI & 9 TI & 10RICVP & Nmax \\
\hline 1 MP & 1 & 1 & 1 & 1.0 & 1.0 & 1 & 1.0 & 1 & 1.0 & 1.0 & 1.077 \\
\hline 2 FCR & 1 & 1 & 1 & 1.0 & 1.0 & 1 & 1.0 & 1 & 1.0 & 1.0 & 1.077 \\
\hline 3NPV & 1 & 1 & 1 & 1.0 & 1.0 & 1 & 1.0 & 1 & 1.0 & 1.0 & 1.077 \\
\hline 4 OMS & 1 & 1 & 1 & 1.0 & 1.0 & 1 & 2.0 & 3 & 4.0 & 5.0 & 1.815 \\
\hline 5 ROI & 1 & 1 & 1 & 1.0 & 1.0 & 1 & 4.0 & 4 & 3.0 & 2.0 & 1.822 \\
\hline 6 PROD & 1 & 1 & 1 & 1.0 & 1.0 & 1 & 1.0 & 1 & 1.0 & 1.0 & 1.077 \\
\hline 7 SBCI & 1 & 1 & 1 & 0.5 & 0.3 & 1 & 1.0 & 1 & 1.0 & 1.0 & 0.891 \\
\hline 8 EI & 1 & 1 & 1 & 0.3 & 0.3 & 1 & 1.0 & 1 & 1.0 & 1.0 & 0.861 \\
\hline 9 TI & 1 & 1 & 1 & 0.3 & 0.3 & 1 & 1.0 & 1 & 1.0 & 1.0 & 0.856 \\
\hline 10 RICVP & 1 & 1 & 1 & 0.2 & 0.5 & 1 & 1.0 & 1 & 1.0 & 1.0 & 0.869 \\
\hline & & & & & & & & & & & 11.420 \\
\hline COL SUM & 10 & 10 & 10 & 7.3 & 7.3 & 10 & 14.0 & 15 & 15.0 & 15.0 & \\
\hline
\end{tabular}

Table 14b Normalized matrix of ten criteria. This table is prepared the way we prepared the table 3 .

\begin{tabular}{|l|c|c|c|c|c|c|c|c|c|c|c|}
\hline & $\mathbf{1 .}$ & $\mathbf{2 . F C R}$ & $\mathbf{3}$ & $\mathbf{4}$ & $\mathbf{5}$ & $\mathbf{6}$ & $\mathbf{7}$ & $\mathbf{8}$ & $\mathbf{9}$ & $\mathbf{1 0}$ & $\begin{array}{c}\text { Priority } \\
\text { vector. }\end{array}$ \\
\hline 1 MP & 0.1 & 0.1 & 0.1 & 0.13 & 0.13 & 0.1 & 0.1 & 0.07 & 0.1 & 0.1 & 0.095 \\
\hline 2 FCR & 0.1 & 0.1 & 0.1 & 0.13 & 0.13 & 0.1 & 0.1 & 0.07 & 0.1 & 0.1 & 0.095 \\
\hline 3 NPV & 0.1 & 0.1 & 0.1 & 0.13 & 0.13 & 0.1 & 0.1 & 0.07 & 0.1 & 0.1 & 0.095 \\
\hline 4 OMS & 0.1 & 0.1 & 0.1 & 0.13 & 0.13 & 0.1 & 0.1 & 0.2 & 0.3 & 0.3 & 0.162 \\
\hline 5 ROI & 0.1 & 0.1 & 0.1 & 0.13 & 0.13 & 0.1 & 0.3 & 0.27 & 0.2 & 0.1 & 0.156 \\
\hline 6 PROD & 0.1 & 0.1 & 0.1 & 0.13 & 0.13 & 0.1 & 0.1 & 0.07 & 0.1 & 0.1 & 0.095 \\
\hline 7 SBCI & 0.1 & 0.1 & 0.1 & 0.06 & 0.03 & 0.1 & 0.1 & 0.07 & 0.1 & 0.1 & 0.077 \\
\hline 8 EI & 0.1 & 0.1 & 0.1 & 0.04 & 0.03 & 0.1 & 0.1 & 0.07 & 0.1 & 0.1 & 0.075 \\
\hline 9 TI & 0.1 & 0.1 & 0.1 & 0.03 & 0.04 & 0.1 & 0.1 & 0.07 & 0.1 & 0.1 & 0.075 \\
\hline 10 RICVP & 0.1 & 0.1 & 0.1 & 0.02 & 0.06 & 0.1 & 0.1 & 0.07 & 0.1 & 0.1 & 0.077 \\
\hline
\end{tabular}


Analytic Hierarchy Process (AHP) Approach For Selection of Open Cast Coal Mine Project

\begin{tabular}{|l|l|l|l|}
\hline $\begin{array}{l}\text { Consistency index CI } \\
=(\mathrm{nmax}-\mathrm{n}) /(\mathrm{n}-1)\end{array}$ & 0.158 & \\
\hline \multicolumn{2}{|l|}{} & & \\
\hline $\begin{array}{l}\text { Random consistency RI =1.98(n- } \\
2) / \mathrm{n}\end{array}$ & 1.584 & \\
\hline \multicolumn{2}{|l|}{ Consistency Ratio = CI/RI } & 0.1 & \\
\hline
\end{tabular}

In the table (no.15) the relative weight (from priority vector) of project P1, P2, P3, P4 \&P5 are shown in the first column for MP (manpower). Similarly, the relative weights for $\mathrm{FCR}\left(2^{\text {nd }}\right.$ colomn $), \mathrm{NPV}\left(3^{\text {rd }}\right.$ column $), \operatorname{OMS}\left(4^{\text {th }}\right.$ column $), \operatorname{ROI}\left(5^{\text {th }}\right.$ column $)$, $\operatorname{PROD}\left(6^{\text {th }}\right.$ column $), \operatorname{SBCI}\left(7^{\text {th }} c o l u m n\right), \operatorname{EI}\left(8^{\text {th }}\right.$ column $), \operatorname{TI}\left(9^{\text {th }}\right.$ column $) \& \operatorname{RICVP}\left(10^{\text {th }}\right.$ column) are shown in the table 15 .

Table 15 Priority matrix $\left(\mathrm{P}_{5 \times 10}\right)$ formed by combining 10 priority vectors.

\begin{tabular}{|l|l|l|l|l|l|l|l|l|l|l|}
\hline & MP & FCR & NPV & OMS & ROI & PROD & SBCI & EI & TI & RICVP \\
\hline P1 & 0.44518 & 0.092 & 0.14364 & 0.2746 & 0.2935 & 0.05716 & 0.38909 & 0.18439 & 0.15417 & 0.33206 \\
\hline P2 & 0.07085 & 0.53183 & 0.23676 & 0.05897 & 0.09637 & 0.1381 & 0.11628 & 0.34878 & 0.44723 & 0.07248 \\
\hline P3 & 0.07388 & 0.04078 & 0.41832 & 0.10552 & 0.10664 & 0.2929 & 0.08276 & 0.18439 & 0.07486 & 0.13065 \\
\hline P4 & 0.19745 & 0.21303 & 0.08134 & 0.15082 & 0.18068 & 0.07101 & 0.12338 & 0.09805 & 0.16956 & 0.38246 \\
\hline P5 & 0.21263 & 0.12236 & 0.12003 & 0.4101 & 0.32281 & 0.44083 & 0.28849 & 0.18439 & 0.15417 & 0.08236 \\
\hline
\end{tabular}

Table 16 Criteria Priority Vector $\left(\mathrm{C}_{10 \times 1}\right)$ a column matrix.

\begin{tabular}{|l|l|}
\hline \multicolumn{1}{|c|}{ Criteria } & \multicolumn{1}{c|}{ Priority vector. } \\
\hline MP & 0.095 \\
\hline FCR & 0.095 \\
\hline NPV & 0.095 \\
\hline OMS & 0.162 \\
\hline ROI & 0.156 \\
\hline PROD & 0.095 \\
\hline SBCI & 0.077 \\
\hline EI & 0.075 \\
\hline TI & 0.075 \\
\hline RICVP & 0.077 \\
\hline
\end{tabular}

If we multiply the Criteria Priority Vector $\left(\mathrm{C}_{10 \times 1}\right)$ by the Priority matrix $\left(\mathrm{P}_{5 \times 10}\right)$, we will get a decision vector $\left(\mathrm{V}_{5 \times 1}\right)$.

As, $\mathrm{P}_{5 \times 10} \mathrm{X} \mathrm{C}_{10 \times 1}=\mathrm{V}_{5 \times 1}$

And we will get the

Decision vector (over all priority vector) $\mathrm{V}_{5 \times 1}$ as shown in table 17

Table.17 Decision vector

\begin{tabular}{|l|}
\hline 2.510881 \\
\hline 2.017702 \\
\hline 1.670474 \\
\hline 1.712083 \\
\hline 2.873851 \\
\hline
\end{tabular}

The table 18 shows the final overall relative weights of the five projects $\mathrm{P} 1, \mathrm{P} 2, \mathrm{P} 3$, P4 \& P5. This table is prepared as per the steps of AHP 
Table 18 Final Ranking of The Five Projects

\begin{tabular}{|c|c|c|}
\hline PROJECT & RELATIVE WEIGHT & RANKS \\
\hline P1 & 2.510881 & 2 \\
\hline P2 & 2.017702 & 3 \\
\hline P3 & 1.670474 & 5 \\
\hline P4 & 1.712083 & 4 \\
\hline P5 & 2.873851 & 1 \\
\hline
\end{tabular}

\section{DISCUSSION OF RESULT}

From the table 18 we can see that the magnitude of project 5 is maximum and hence project $5(\mathrm{P} 5)$ is the best project. In the descending order second highest magnitude is 2.510881. Therefore, project $1(\mathrm{P} 1)$ is the second best project. In this way we can rank the five projects in order of the magnitude from table 18. But here we have to keep in mind that these choices depend on making of pairwise comparison matrix by the team of decision maker. The perception of decision makers may vary from one team to another. Even the same team of decision maker may change the value of pairwise comparison matrix and see the effect of it the way we make sensitivity analysis in operations research.

This research paper represents how AHP can be used for selection of open cast mine project. A case example has been taken to justify the workability of this AHP approaches for open cast mine project selection. AHP method selects project no. 5 is the best project and project no. 1 is the second best project considering their magnitude in the overall priority vector. This only corroborates the importance of application of quantitative methods in decision making process.

However, the case example has been developed considering five projects and ten criteria only. The more the number of criteria the more this will be appropriate in selection of projects. Because in that case they will reflect all possible intrinsic and extrinsic issues involving project selection. But to get a perfect result the number of open cast mine projects should not be more than 9 as from the psychological point of view as an individual cannot simultaneously compare more than $7 \pm 2$ objects without being confused[20].

\section{CONCLUSION}

The multiple attribute decision making (MADM) is an important area in modern decision making science. It has been widely applied in many fields such as economics, environment and management. It has received more and more attention since its appearance. This method is clear in structure and easy to understand. Nevertheless, it requires pairwise comparisons between criteria and alternatives in order to set up decision matrices. This results in huge computation and may lead to low accuracy. In some cases, the equal weight is usually adopted for simplicity. In practice, different criteria have different importance, so it is not reasonable to assign them equal weights. While for the weights selected subjectively, one can hardly guarantee and their objectivity and reasonability during decision making process.

Fuzziness and uncertainties are often encountered in practice. During the decision making process, people often reluctant or unable to assign accurate values in the evaluation process due to the following typical reasons ; the social environment is rather complex ; the people thinking is usually uncertain, ambiguity and vague; the expert's knowledge might be limited. People prefer to provide their evaluation in 
linguistic terms. For example, one would like to use "good", "very good", "medium", "bad", "very bad", to express his/her preference in evaluating the project. Therefore fuzzy set theory [21] can be applies in further research work to deal with the uncertainty and vagueness.

\section{REFERENCES}

[1] Joseph S. Pliskin \& Dov Dori (1982) Ranking Alternative Warehouse Area Assignments: A Multiattribute Approach, A I I E Transactions, 14:1, 19-26, https://doi.org/10.1080/05695558208975034

[2] Pearson, A. A Note on Project Selection in Research and Development Post-Rothschild, Journal of Operational Research Society, 24(2), 295-297. https://doi.org/10.1057/jors.1973.46

[3] Hindle. D, An Efficient Procedure for Different Weigh of Committee member's Subjective Estimates, International Journal of Operations Research, 26(4), (1975) 759-762.

[4] Yasanur Kayikci, A conceptual model for intermodal freight logistics centre location decisions, Procedia Social and Behavioural Sciences (2010) 6297-6311.

[5] Licinio da Silva Portugal, Andréa Vaz Morgado, Orlando Lima Júnior, "Location of cargo terminals in metropolitan areas of developing countries: the Brazilian case", Journal of Transport Geography, Volume 19, Issue 4, 2011, Pages 900-910, https://doi.org/10.1016/j.jtrangeo.2010.11.005

[6] Ali Yousefi, and Abdollah Hadi-Vencheh, An integrated group decision making model and its evaluation by DEA for automobile industry, Expert Systems with Applications, 37 (2010) 8543-8556.

[7] Mehmet Ekmekcioglu, Tolga Kaya and Cengiz Kahraman, "Fuzzy multicriteria disposal method and site selection for municipal solid waste", Waste Management, 30 (2010), 1729-1736.

[8] Reza Rostamzadeh and Saudah Sofian, Priortizing effective 7Ms to improve production systems performance using fuzzy AHP and fuzzy TOPSIS(case study), Expert Systems with applications ,38(2011)5166-5177.

[9] Nahid Mohajeri and Gholam R. Amin, Railway station site selection using analytical hierarchy process and data envelopment analysis, Computers \& Industrial Engineering, 59 (2010) 107-114.

[10] Chin-Nung Liao and Hsing -Pei Kao, Supplier selection model using Taguchi loss function, analytical hierarchy process and multi-choice goal programming, Computers \& Industrial Engineering, 58 (2010) 571-577.

[11] Semih Onut and Selin Soner, Transshipment site selection using the AHP and TOPSIS approach under fuzzy environment, Waste management, 28 (2008) 1552-1559.

[12] Vukotic Ivana and Kecojevic Vladislav, Evaluation of rope shovel operators in surface coal mining using a Multi-Attribute Decision -Making model, International journal of mining science and technology, 24 (2014) 259-268.

[13] A. Bascetin, A decision support system using analytical hierarchy process (AHP) for the optimal environmental reclamation of an open-pit mine, Environment Geology, 52 (2007) 663-672.

[14] Mahmut Yavuz, Melih Iphar and Guner Once, The optimum support design selection by using AHP method for the main haulage road in WLC Tunebilek colliery, Tunnelling and Underground Space Technology, 23 (2008) 111-119.

[15] Hamdy A.Taha, Operations Research An Introduction, Pearson Education, seventh edition (2004). 
[16] Anderson, Sweeney, Williams \& Martin, An Introduction to Management Science Quantitative Approaches to Decision Making, Thompson South Western, 12th Edition (2008).

[17] Anderson D R , Dennis J Sweeney, Thomas A .Williams, An Introduction to Management Science Quantitative Approaches to Decision Making, Thompson, Indian Edition, Eleventh Edition, (2005).

[18] Aderoba A A , Public Selection of Private Projects for foreign Exchange Allocation, Industrial Engineering journal, XX(12) 1991

[19] Satya Mandal \& Kampan Mukherjee, Multi-attribute Project selection decision A D S S Framework, International Journal of Management and systems, 10, (1) 1994, 89-100.

[20] Welford .A .T. and Birren.J.E, Behviour, ageing and the nervous System, Charles C. Thomas, III, (1965).

[21] Parul Gupta, Moradabad, R.K. Srivastava, Motilal. Analysis of Customer Satisfaction In Hotel Service Quality Using Analytic Hierarchy Process (AHP), International Journal of Industrial Engineering Research and Development, 2(1), 2016, pp. 59-68.

[22] Rajnish Katarne and Dr. Jayant Negi. Determination of Importance of Criteria: Analytic Hierarchy Process (AHP) In Technological Evolution of Automobile Steering, International Journal of Industrial Engineering Research and Development, 4(1), 2013, pp. 10-18.

[23] Ayman A. Abdul-Mawjoud and Mohammed G. Jamel. Using The Analytic Hierarchy Process and GIS For Decision Making In Rural Highway Route Location, International Journal of Industrial Engineering Research and Development, 7(2), 2016, pp. 359-375.

[24] Zadeh, L.A. and Belleman R.E. Decision Making in a Fuzzy Environment, Management Science, 17 (4) B141-B164, (1965) B141-B164. 